Check for updates

Cite this: RSC Adv., 2018, 8, 5776

Received 12th December 2017

Accepted 26th January 2018

DOI: $10.1039 / c 7 r a 13263 h$

rsc.li/rsc-advances

\section{Facile construction of a hyperbranched poly(acrylamide) bearing tetraphenylethene units: a novel fluorescence probe with a highly selective and sensitive response to $\mathrm{Zn}^{2+} \uparrow$}

\author{
Xuejing Liu, ${ }^{a}$ Yuangong Zhang, ${ }^{a}$ Haijing Hao, ${ }^{a}$ Wanju Zhang, ${ }^{b}$ Libin Bai, ${ }^{\text {*ab }}$ \\ Yonggang $\mathrm{Wu}^{a}{ }^{a}$ Hongchi Zhao, ${ }^{a}$ Hailei Zhang ${ }^{*}{ }^{* a}$ and Xinwu $\mathrm{Ba}^{a}$
}

\begin{abstract}
Thermo-responsive hyperbranched copoly(bis $(N, N$-ethyl acrylamide)/( $N, N$-methylene bisacrylamide)) (HPEAM-MBA) was synthesized by using reversible addition-fragmentation chain-transfer polymerization (RAFT). Interestingly, the zinc ion $\left(\mathrm{Zn}^{2+}\right)$ was found to have a crucial influence on the lowest critical solution temperature (LCST) of the thermo-responsive polymer. The tetraphenylethylene (TPE) unit was then introduced onto the backbone of the as-prepared thermo-responsive polymer, which endows a $\mathrm{Zn}^{2+}$-responsive "turn-off" effect on the fluorescence properties. The TPE-bearing polymer shows a highly specific response over other metal ions and the "turn-off" response can even be tracked as the concentration of $\mathrm{Zn}^{2+}$ reduces to $2 \times 10^{-5} \mathrm{M}$. The decrement of fluorescence intensity was linearly dependent on the concentration of $\mathrm{Zn}^{2+}$ in the range of $4-18 \mu \mathrm{mol} \mathrm{L}{ }^{-1}$. The flexible, versatile and feasible approach, as well as the excellent detection performance, may generate a new type of $\mathrm{Zn}^{2+}$ probe without the tedious synthesis of the moiety bearing $\mathrm{Zn}^{2+}$ recognition units.
\end{abstract}

\section{Introduction}

Zinc is widespread in nature, such as in food (vegetables, wheat, fruit, and milk powder), beverages (beer, and wine), animals (cows, and chickens), soil, minerals and the human body. The detection of zinc has raised attention in fields including wastewater treatment, food analysis, environmental monitoring and medical treatment. ${ }^{1-3}$ Zinc content in soil and irrigation water will have an effect on the quality of wheat. Zinc in milk powder has greatly affected the growth of infants. Zinc is one of the important nutritional attributes in many beverages. The zinc ion is the second most abundant transition metal ion in the body and plays an active role in various physiological processes including cell growth, adaptive immunity, gene transcription, apoptosis and neurotransmission. ${ }^{4-7}$ An imbalance in zinc ions is closely associated with diseases, such as diabetes and neurodegenerative diseases. ${ }^{\mathbf{8 - 1 0}}$ Therefore, the accurate and sensitive detection of zinc ions would be significant for practical application, such as exploring disease mechanisms, food analysis and environmental monitoring. A number of analytical

${ }^{a}$ College of Chemistry \& Environmental Science, Hebei University, Baoding, Hebei Province 071002, P. R. China.E-mail: haileipoly@126.com; zhonggou556@hbu.edu. $\mathrm{cn}$

${ }^{b}$ Hubei Key Laboratory for Processing and Application of Catalytic Materials, Huanggang Normal University, Huanggang, Hubei Province, 438000, P. R. China

$\dagger$ Electronic supplementary information (ESI) available. See DOI: 10.1039/c7ra13263h techniques have been employed to detect and quantify zinc in biological systems, including inductively coupled plasma atomic emission spectroscopy, atomic absorption spectrophotometry and radioisotope detection. ${ }^{11-14}$ Comparing with these methods, fluorescent sensor with real-time monitoring, high sensitivity and noninvasive, shows attractive prospect in the detection of intracellular ion levels. ${ }^{15-17}$ The past two decades have witnessed the development of a series of small moleculebased fluorescent zinc ion probes. These synthetic $\mathrm{Zn}^{2+}$ probes possessing diverse colors, response mechanisms, kinetics, and binding affinities, have proven to be valuable tools. ${ }^{18-32}$ Despite the progress, for selectively detecting the zinc ions in live cells, a suitable group being of recognition in zinc ion has to be contained in the fluorescent probes. Thus, there remains much to be done to develop novel probes, or seek other way for circumventing this problem.

Since zinc ion is of $3 \mathrm{~d}^{10}$ electron configuration, it is prone to chelate with other elements $(\mathrm{N}, \mathrm{S}, \mathrm{O})$ and thereby inducing changes in the fluorescence properties. Zinc ion can also bind with the polymers and result in the conformational changes or cross-linking structures. Zuckermann et al. ${ }^{33}$ introduced a highaffinity zinc-binding function on a peptoid ( $N$-substituted glycine polymer) two-helix bundle, where the conformational change in polymers was systematically investigated. Yano et al. ${ }^{\mathbf{3 4}}$ reported a $\mathrm{Zn}^{2+}$ salt of ethylenemethacrylic acid ionomer which possesses pressure responsiveness. The response was caused by the change of coordination structure around zinc ion. The 
conformational change may also be able to trigger a fluorescence change, and thereby endow a "turn on" or "turn off" response as the polymers binding with the $\mathrm{Zn}^{2+}$ in fluorescence polymers.

In this work, we synthesized a backbone temperaturesensitive hyperbranched polyamide in which the temperature sensitivity is imparted by temperature-responsive backbone. ${ }^{35}$ The conformation of polymer chains will be transformed from the extended state into aggregation as the temperature exceeding lower critical solution temperature (LCST). More importantly, we found that the LCST i.e. conformational change in polymers can also be affected by the ions due to the existence of $\mathrm{N}$ element. Fortunately, in comparison with other cations, $\mathrm{Zn}^{2+}$ exhibited a critical influence on LCST. Aggregationinduced emission (AIE) fluorogens firstly presented by Benzhong Tang ${ }^{36-39}$ have attracted considerable interest in the fluorescence probes field for its unique fluorescence emission mechanism. The AIE fluorescent probes can be conferred with "responsive or recognition" feature by introducing a special group that affects the molecular aggregation after reacting with other compound. Taking advantage of AIE feature, Benzhong Tang's group ${ }^{\mathbf{4 0}}$ synthesized a new probe (DEVD-TPE) that might monitor the cell apoptosis. Bo Tang's group ${ }^{\mathbf{4 1}}$ prepared a rapidresponse fluorescent probe for hydrogen peroxide. Herein, the introduction of tetraphenylethene into the backbone of the thermo-responsive poly(acryl amide) may create a response of $\mathrm{Zn}^{2+}$ to the fluorescence change. A hyperbranched polymer bearing tetraphenylethene units was synthesized via RAFT method. The zinc ion stimulates the conformational change of polymer chains and thereby prohibit the intramolecular rotations of AIE units. The TPE-bearing polymer can monitor the zinc ion via the decrease in fluorescence intensity, which can be called as a "turn off" response. The development of the AIEbased fluorescent probe for detection of zinc ion without resorting to traditional $\mathrm{Zn}^{2+}$ recognition units. The as-prepared polymer can be used as an efficient fluorescent probe for detecting the $\mathrm{Zn}^{2+}$ on trace levels.

\section{Experimental}

\section{Materials}

$N, N$-dimethylformamide (DMF), ammonium persulfate (APS), $N, N^{\prime}$-methylene bisacrylamide (MBA) and acetone (95\%, Tianjin kemiou chemical reagent Co., Tianjin, China) were purified before use. Deuterium Oxide, and Methanol- $d_{4}$ were purchased from Sinopharm Chemical Reagent Co., Ltd (Shanghai, China). All the salts were purchased from Tianjin Fuchen Chemical Reagents Factory and used as received. $N, N^{\prime}$-ethyl bisacrylamide (EBA), and $S, S^{\prime}$-bis( $a$, $a$-dimethyl- $a^{\prime \prime}$-acetic acid)-trithiocarbonate (BDAAT) were synthesized following the literature procedure and used as chain transfer agent (CTA) in RAFT polymerization. ${ }^{42}$ Tetraphenylethene with one allyloxy group and one hydroxy groups (4-(2-(4-(allyloxy)phenyl)-1,2-diphenylvinyl) phenol, TPEAH) was synthesized following the literature procedure and the ${ }^{1} \mathrm{H}$ NMR and MS spectra are given in ESI. $\dagger^{43}$ Deionized water was double-distilled before use.
Synthesis hyperbranched copoly(bis( $N, N$-ethyl acryl amide)/ ( $N, N$-methylene bisacrylamide)) (HPEAM-MBA)

Polymerization was carried out in a glass tube that sealed with a rubber cap under nitrogen atmosphere. EBA (336 mg, $2 \mathrm{mmol}$ ), MBA (46.2 mg, $0.3 \mathrm{mmol}$ ), BDAAT (32.43 $\mathrm{mg}, 0.115 \mathrm{mmol}$ ), APS (52.44 mg, $0.23 \mathrm{mmol})$ and DMF $(8 \mathrm{~mL})$ were added to a Schlenk tube. Oxygen was removed by repeated vacuumnitrogen cycles. Then, the polymerization was conducted at $70{ }^{\circ} \mathrm{C}$ in an oil bath for $24 \mathrm{~h}$. Afterwards, the obtained polymer was precipitated by dropping the solution into a large excess of acetone to remove the excessive monomers and impurities. The precipitated polymer was separated by centrifugation, and then dissolved in water. The final product HPEAM-MBA was given after lyophilization (Scheme 1).

Synthesis hyperbranched copoly(bis( $N, N$-ethyl acryl amide $) / 4$ (2-(4-(allyloxy)phenyl)-1,2-diphenylvinyl)phenol) (HPEAMTPEAH)

EBA (336 mg, $2 \mathrm{mmol}$ ), MBA (46.2 mg, $0.3 \mathrm{mmol}$ ), BDAAT (32.43 mg, $0.115 \mathrm{mmol}$ ), APS (52.44 mg, $0.23 \mathrm{mmol})$, ТРЕAH (5 mmol, $20 \mathrm{mg}$ ) and DMF ( $8 \mathrm{~mL}$ ) were added to a Schlenk tube. Oxygen was removed by repeated vacuum-nitrogen cycles. Then, the polymerization was conducted at $70{ }^{\circ} \mathrm{C}$ in an oil bath for $24 \mathrm{~h}$. Afterwards, the obtained polymer was precipitated by dropping the solution into a large excess of acetone to remove the excessive monomers and impurities. The precipitated polymer was separated by centrifugation, and then dissolved in water. The final product HPEAM-TPEAH was given after lyophilization (Scheme 2).

\section{Measurement of lower critical solution temperature (LCST)}

LCSTs were defined as the temperature corresponding to $50 \%$ transmittance of aqueous solution during the heating process.
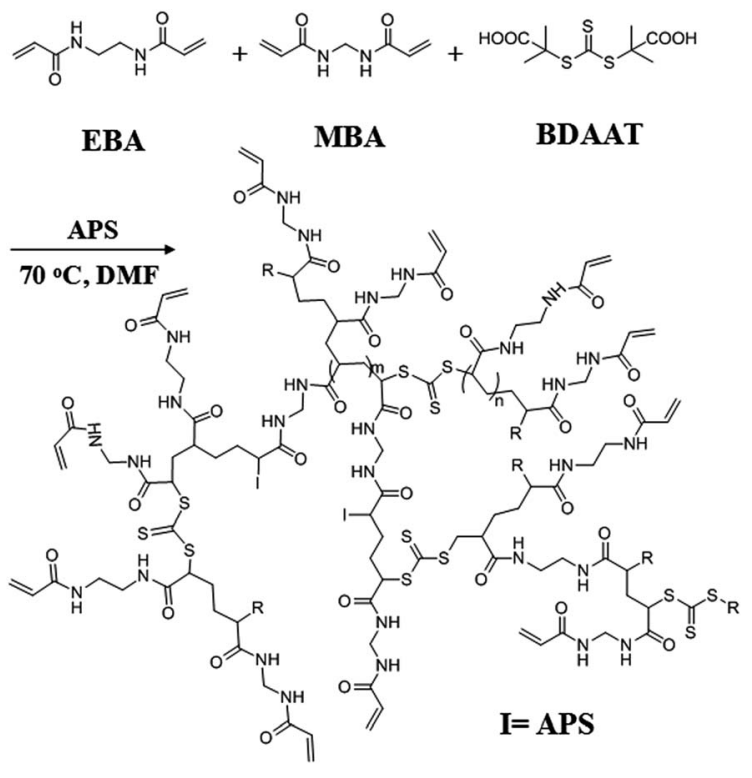

HPEAM-MBA 

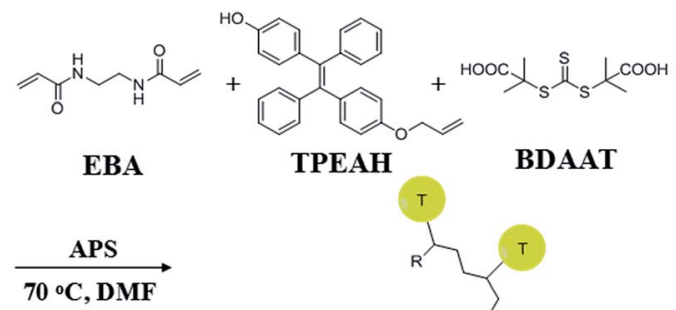

$$
\text { TPEAH }
$$

BDAAT

.

U-visible 2550 Spectrophotometer (Shimadzu, Japan) at $500 \mathrm{~nm}$ with the heating rate as $0.1{ }^{\circ} \mathrm{C} \mathrm{min}^{-1}$, and the UV-vis spectra of polymer solution was also obtained through same spectrophotometer from $250 \mathrm{~nm}$ to $400 \mathrm{~nm}$. Equivalent amounts of polymers were added to $4.0 \mathrm{~mL}$ of aqueous solution of different salts. The mixture was cooled at $4{ }^{\circ} \mathrm{C}$ for $10 \mathrm{~min}$ to ensure that the polymer was dissolved completely.

\section{Cytotoxicity study}

The cytotoxicity of HPEAM-TPEAH on Hela cells was examined as follows: Hela cells $(5 \times 103$ cells $)$ in $100 \mu \mathrm{L}$ of DMEM containing $10 \%$ FCS were plated in a 96 -well plate and incubated for $24 \mathrm{~h}$ in a humidified atmosphere of $5 \% \mathrm{CO}_{2}$ in air at $37{ }^{\circ} \mathrm{C}$ (Sanyo, Model MCO-18AIC, Japan) Then $100 \mu \mathrm{L}$ of a HPEAMTPEAH in DMEM containing $10 \%$ FCS and $2 \%$ DMSO was added to each well. Incubation was carried out for $24 \mathrm{~h}$ at a HPEAM-TPEAH concentration of $0.5 \mu \mathrm{M}$ (final DMSO content was $1 \%$ in all cases). Cells without HPEAM-TPEAH treatment were used as control group. After $24 \mathrm{~h}$ of treatment, MTT dye solution $\left(20 \mu \mathrm{L}, 5 \mathrm{mg} \mathrm{mL}{ }^{-1}\right)$ was added to each cell. Cells were incubated for another $4 \mathrm{~h}$ and then analyzed using a microplate spectrophotometer (BioRad Model 3550, USA) at $570 \mathrm{~nm}$. The percentage cell survival was calculated by normalization with respect to the value for no HPEAM-TPEAH treatment.

\section{Characterization}

Infrared spectroscopy was measured on a Varian 640-IR Fourier infrared spectrometer (Varian, Palo Alto, CA, USA) by using $\mathrm{KBr}$ pellets and solution in $\mathrm{D}_{2} \mathrm{O}$. $\mathrm{CaF}_{2}$ transmission windows and $0.05 \mathrm{~mm}$ Mylar spacers were used. For each spectrum, 256 interferograms of $2 \mathrm{~cm}^{-1}$ resolution were co-added. From the spectrum of each sample, a corresponding $\mathrm{D}_{2} \mathrm{O}$ spectrum was subtracted. All the spectra were baseline-corrected and normalized. All data processing was performed with Resolution software. The samples were investigated at mass concentration of $0.5 \mathrm{wt} \%$ in $\mathrm{D}_{2} \mathrm{O} .{ }^{1} \mathrm{H}$ NMR spectra were recorded on a Bruker AVANCE-600 $600 \mathrm{MHz}$ spectrometer (Bruker, Germany). The chemical shifts are given in parts per million (ppm). Fluorescence spectrum analysis was measured on the RF-5301-PC (Shimadzu, Japan) fluorescence spectrometer lighttransmittance of the polymer solution was measured on a temperature-controlled. Molecular weight, polydispersity, Mark-Houwink index $(\alpha)$ and intrinsic viscosity (IV) were determined by Viscotek 270-MDSEC (Malvern Instruments Ltd., Malvern, US) equipped with the differential refractive index (RI), viscometer, and two-angle light scattering (LS, Malvern Instruments Ltd., Malvern, US) triplet detectors. The eluent was $0.1 \mathrm{~mol} \mathrm{~L}^{-1} \mathrm{NaNO}_{3}$ aqueous solution at a flow rate of 1 $\mathrm{mL} \min ^{-1}$ at $15^{\circ} \mathrm{C}$. For MDSEC, narrow dispersion polyethylene oxide std-PE022K was used to calibrate the instrument. TEM studies of copolymers were performed on a Tecnai G2 F20 STWIN (FEI Company, Hillsboro, USA) dedicated to cryogenic temperatures, operated at an acceleration voltage of $200 \mathrm{kV}$ at low electron-dose conditions. A small drop of clear and cloudy copolymers solution $\left(1 \mathrm{mg} \mathrm{mL} \mathrm{mL}^{-1}\right)$ containing $1 \mathrm{wt} \%$ phosphotungstic acid (PTA) was placed on the Cu grid with holey carbon film held by tweezers of the vitrification system Vitrobot (FEI Company, Hillsboro, USA). DLS measurements were performed on a Brookhaven BI-200 goniometer (Brookhaven, New York, USA) with vertically polarized incident light of wavelength $\lambda=$ $532 \mathrm{~nm}$ supplied by a helium-neon laser operated at $75 \mathrm{~mW}$ and a Brookhaven BI-4700 AT digital autocorrelator (Brookhaven, New York, USA).

\section{Results and discussions}

In a previous study, hyperbranched poly(bis $(N, N$-propyl acryl amide $))^{44}$ and poly(bis( $N, N$-ethyl acrylamide $\left.)\right)^{45}$ had been successfully synthesized with high yield by reversible additionfragmentation chain transfer polymerization (RAFT) method. In addition, the lower critical solution temperature (LCST) often ranges from 19 to $28{ }^{\circ} \mathrm{C}$, and 6 to $17{ }^{\circ} \mathrm{C}$, respectively. In this study, the synthesis hyperbranched copoly(bis $(N, N$-ethyl acryl amide) $/(N, N$-methylene bisacrylamide)) (HPEAM-MBA) was conducted in order to achieve a desirable LCST near human body temperature. Fortunately, the LCST of HPEAM-MBA is determined to be $36.4^{\circ} \mathrm{C}$ (details were shown in the ESI $\dagger$ ).

It is known that the monomer possessing a multi vinyl monomer (MVM) is usually employed to fabricate polymers with crosslinked network structures, even if only small amounts of MVM participates in the free radical polymerization. However, Sherrington ${ }^{46}$ and Guan $^{47}$ respectively prepared hyperbranched polymers with MVM as branching units via a chain transfer controlled free radical polymerization. The crosslinking was effectively inhibited by using thiol or catalytic chain transfer catalyst species. In Sato's study, ${ }^{4-51}$ the MVM was also used as the branching species in which the radical 
polymerization was well controlled by a chain termination. Recently, controlled free radical polymerization was used in the MVM reaction system, which is able to reduce the reaction rate and avoid cross-linking in polymerization. In addition, the preparation of hyperbranched polymers can also be well controlled by copolymerization with other monomers via living polymerization. For an example, Wang and Howdle ${ }^{52}$ synthesized hyperbranched polymers with highly branched structures via atom transfer radical polymerization (ATRP). In our study, RAFT polymerization was adopted for the synthesis of hyperbranched copoly(bis $(N, N$-ethyl acryl amide $) /(N, N$-methylene bisacrylamide)) (HPEAM-MBA). As shown in Scheme 1, the RAFT polymerization of MVM consists of three stages: initiating, propagation and terminal stage. The feed ratio of [monomer] : [CTA] reaches $20: 1$ in system. The addition of BDAAT effectively reduced the rate of the free radical polymerization and avoided the crosslinking reaction. The polymerization was carried out in $N, N$-dimethyl formamide (DMF) for $24 \mathrm{~h}$, the resulting polymers were obtained by a precipitation method in acetone. HPEAM-MBA, a polymer with LCST $=36.4{ }^{\circ} \mathrm{C}, M_{\mathrm{w}}=$ $4.33 \times 10^{4}\left(M_{\mathrm{w}} / M_{\mathrm{n}}=1.22\right)$, was well characterized by FTIR, ${ }^{1} \mathrm{H}$ $\mathrm{NMR}$ and ${ }^{13} \mathrm{C}$ NMR, and the details were shown in the ESI, $\uparrow$ respectively. The Mark-Houwink index $(\alpha)$ was calculated as 0.256 , matches well with the inherent character of hyperbranched polymers. ${ }^{53,54}$

The nitrogen in the backbone of as-prepared polymer is able to coordinate with metal ion to form $\mathrm{M}^{n+}-\mathrm{N}_{x}$ complex and result in the changes in hydration. Therefore, the LCST of HPEAMMBAs may also be changed by the addition of metal ions. The influence of metal ions, including $\mathrm{Na}^{+}, \mathrm{K}^{+}, \mathrm{Mg}^{2+}, \mathrm{Ca}^{2+}, \mathrm{Mn}^{2+}$, $\mathrm{Fe}^{2+}, \mathrm{Zn}^{2+}$, on the LCST was investigated. $\mathrm{Zn}^{2+}$ was selected as a represent metal ion whose turbidity curves that reflect the influence of its concentration on the LCST values are shown in Fig. 1. As expected, the turbidity curves are shifted to high temperature with the concentration of $\mathrm{Zn}^{2+}$ increasing. The turbidity curves of other metal ions are displayed in the ESI $\dagger$ respectively. After extracted the LCST values, the plot of LCST

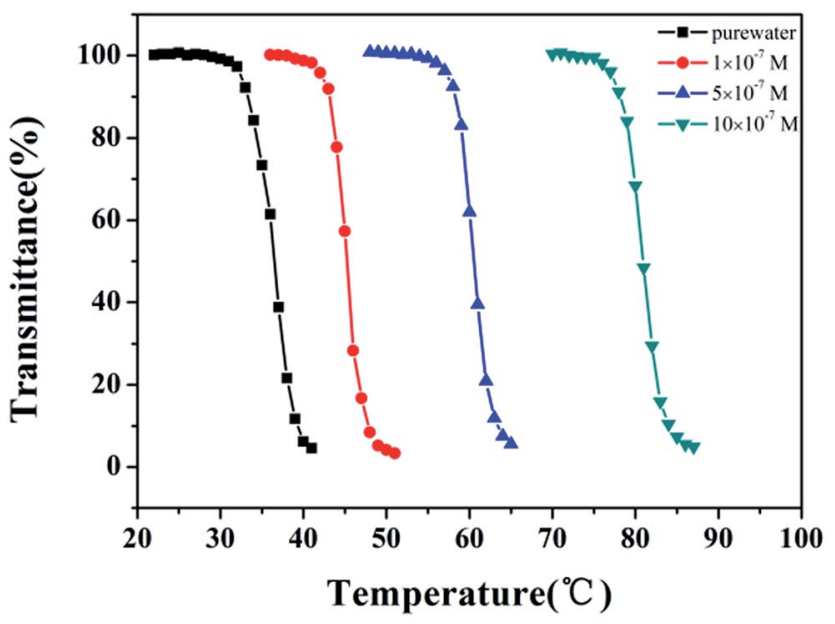

Fig. 1 The curves of transmittance versus temperature of HPEAMMBA solution containing $\mathrm{Zn}^{2+}$. Polymer concentration: $5 \mathrm{mg} \mathrm{mL}^{-1}$; heating rate: $0.1^{\circ} \mathrm{C} \mathrm{min}^{-1}$. values against concentration are illustrated in Fig. 2. It can be observed from the Fig. 2 that all of these metal ions exhibit the hydrotropy ability which can be owing to the salting-in effect. The sequence salting-in effect is $\mathrm{Fe}^{2+}<\mathrm{Ca}^{2+}<\mathrm{Mg}^{2+}<\mathrm{Mn}^{2+}<\mathrm{K}^{+}$ $\approx \mathrm{Na}^{+} \ll \mathrm{Zn}^{2+}$, which is consistent with the typical Hofmeister cation series. ${ }^{55-57}$ It should be noted that the tendency of the plots of LCST vs. $\left[\mathrm{Zn}^{2+}\right]$ displays a significant difference over than those of other metal ions that the LCST is dramatically increased even $\left[\mathrm{Zn}^{2+}\right]<1 \times 10^{-5} \mathrm{M}$.

In order to compare the influence of $\mathrm{Zn}^{2+}$ on the LCST with other metal ions more quantitatively, the parameter $S$ (named sensitivity) is introduced and defined as the reciprocal of $N$ when the transmittance $\%$ of the solution is $50 \%$. For getting the parameter $S$, the transmittance $\%$ of the solution under different concentration of metal ions was recorded and shown as Fig. 3. All of the curves display a similar tendency that the transmittance\% of the solution increases as the $N_{\mathrm{Zn}^{2+}}$ ascends. Also, the temperature affects the amount of the $\mathrm{Zn}^{2+}$. Accompany with temperature of the solution rising up, the $N_{\mathrm{Zn}^{2+}}$ obviously increase. As pointed out in the aforementioned part, high temperature will destroy the hydrogen bonds between the water molecules and amide groups, which means the hydrophobicity of HPEAM-MBAs is proportional to the temperature of solution, therefore the more $N_{\mathrm{Zn}^{2+}}$ is needed as the temperature getting higher. The curve of $N_{\mathrm{Zn}^{2+}}$ with temperature is inserted into the lower right corner of Fig. 3. According with the definition of $S$, the $N_{\mathrm{Zn}^{2+}}$ decreases as the increase of $S$. The curves of transmittance $\% v s$. $N$ of other metals are in the ESI $\dagger$ and display the similar tendency to that in Fig. 3. Although the value of $S$ is the highest as the temperature is closed to LCST, the $S_{\mathrm{Zn}^{2+}}$ $S_{\text {metals }}$ is not the highest value which reveals that the HPEAMMBAs solution does not display good selectivity towards $\mathrm{Zn}^{2+}$. Encouragingly, the value of the $N_{\mathrm{Zn}^{2+}}$ is far below the $N$ of other metals when the temperature of solution is 20 degrees above the LCST, and the ratio of $S_{\mathrm{Zn}^{2+} / S_{\text {metals }}}$ can reach $1.28 \times 10^{3}$. To

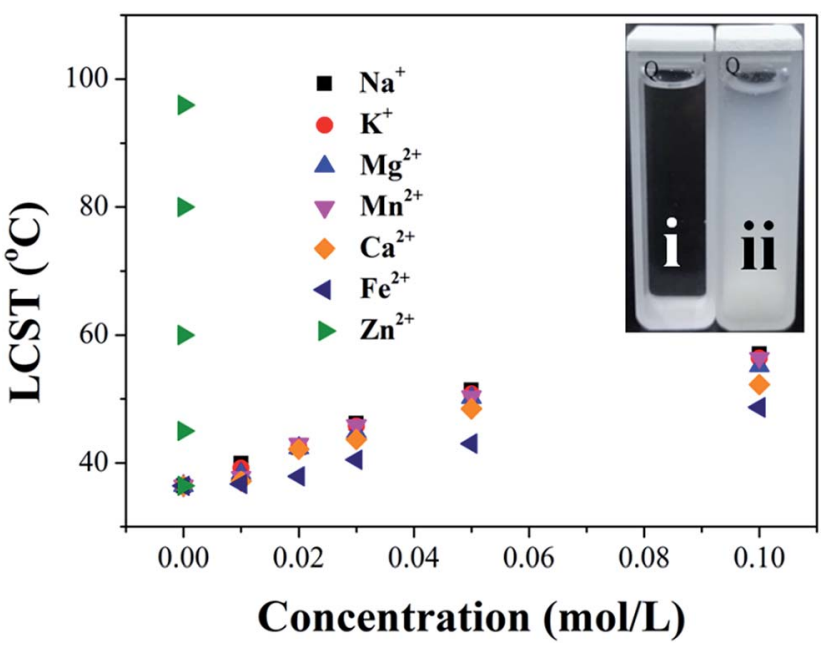

Fig. 2 Influence of different cations $\left(\mathrm{Na}^{+}, \mathrm{K}^{+}, \mathrm{Mg}^{2+}, \mathrm{Ca}^{2+}, \mathrm{Mn}^{2+}, \mathrm{Fe}^{2+}\right.$ and $\mathrm{Zn}^{2+}$ ) on the LCST of HPEAM-MBA ((i) shows the HPEAM-MBA solution when the temperature is lower than LCST; (ii) shows the HPEAM-MBA solution when the temperature is higher than LCST). 


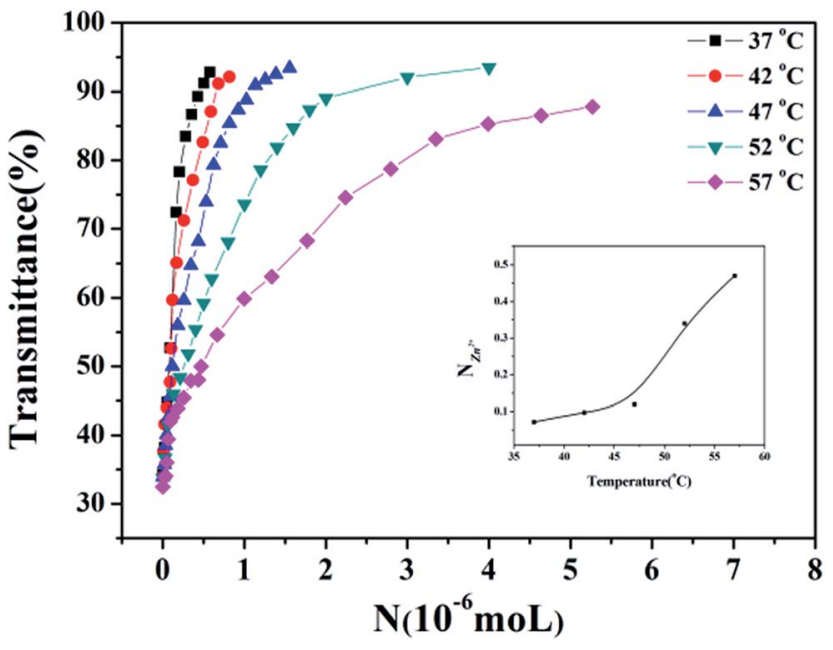

Fig. 3 The curves of transmittance\% vs. $\mathrm{N}_{\mathrm{Zn}^{2+}}$ of HPEAM-MBA at different temperatures. Polymer concentration: $5 \mathrm{mg} \mathrm{mL}^{-1}$.

graphically show the selectivity of HPEAM-MBAs solution towards $\mathrm{Zn}^{2+}$, the $S_{\mathrm{Na}^{+}}$is chose as the reference because that the $\mathrm{Na}^{+}$is the most abundant ion in the human body. As shown in Fig. 4, the ratio of $S_{\mathrm{Zn}^{2+}} / S_{\mathrm{Na}^{+}}$is $5.75 \times 10^{2}$ when the temperature is $57^{\circ} \mathrm{C}$. These results indicate that HPEAM-MBAs solution is of high sensitivity in assessing $\mathrm{Zn}^{2+}$, and the HPEAM-MBAs solution can selectively recognize the $\mathrm{Zn}^{2+}$ when the environment temperature is 20 degrees above the LCST.

Infrared absorption spectra was employed to investigate the interaction of HPEAM-MBA and $\mathrm{Zn}^{2+}$. Fig. 5(A) shows the infrared absorption spectrum of HPEAM-MBA (in $\mathrm{KBr}$ ). The characteristic adsorptions at $1652 \mathrm{~cm}^{-1}$ represents the stretching vibration of $\mathrm{C}=\mathrm{O}$, the peak located at $1541 \mathrm{~cm}^{-1}$ corresponds to $\mathrm{C}-\mathrm{N}$ stretching vibration in the trans-associated secondary amide, and the signal at $1439 \mathrm{~cm}^{-1}$ is the $\mathrm{N}-\mathrm{H}$ bending vibration in cis-amide. Fig. 5(B) is the infrared absorption spectra of HPEAM-MBA measured in $\mathrm{D}_{2} \mathrm{O}$, and

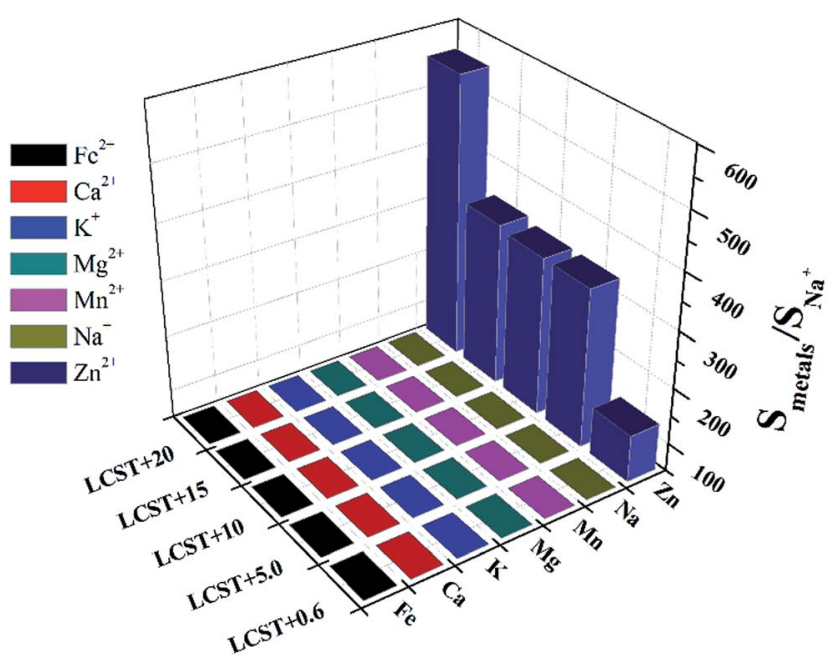

Fig. 4 The three-dimensional histogram of temperature vs. $S_{\text {metals }} / S_{\mathrm{Na}^{+}}$.
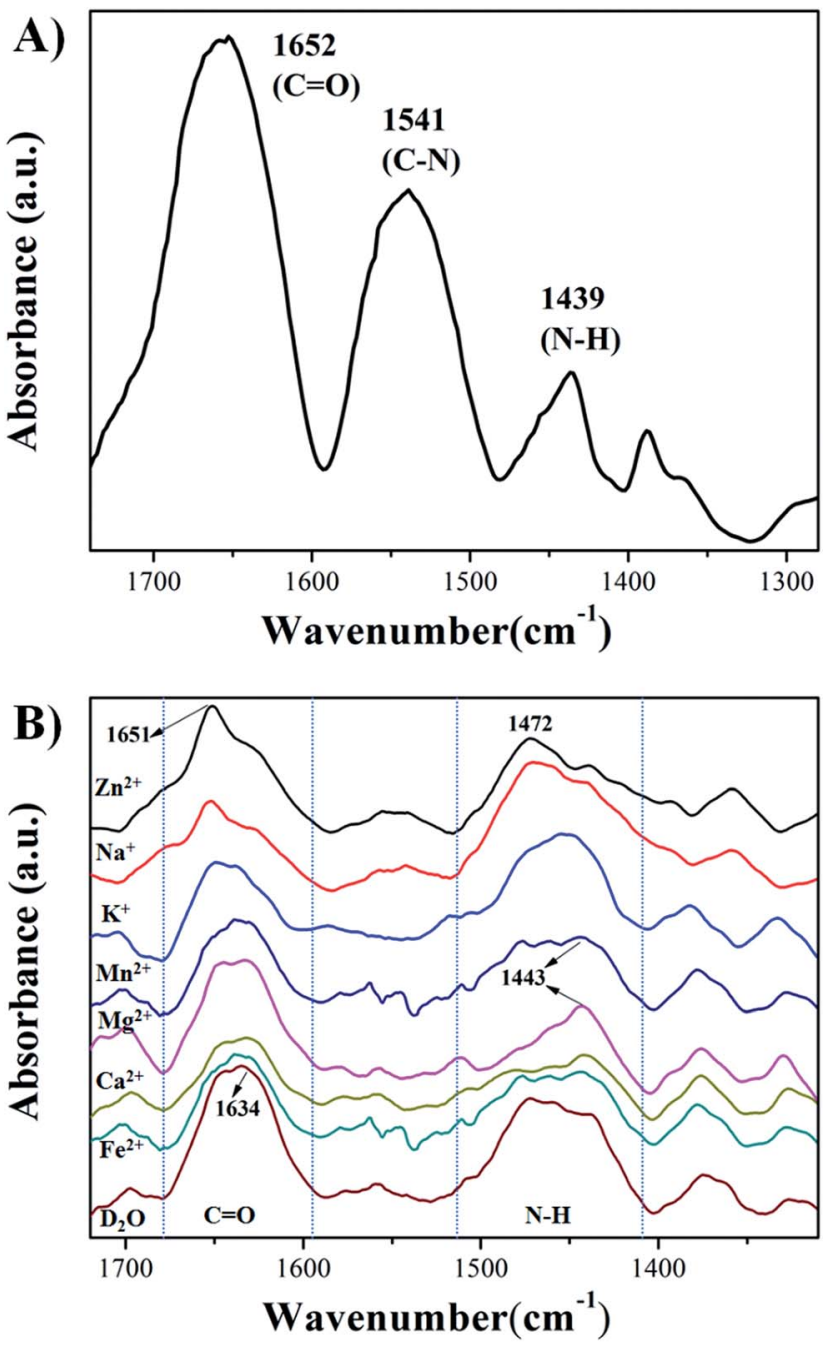

Fig. 5 Infrared absorption spectra of HPEAM-MBA ((A) shows the infrared absorption spectrum of HPEAM-MBA measured in $\mathrm{KBr}$; (B) shows the infrared absorption spectrum of HPEAM-MBA measured in $\mathrm{D}_{2} \mathrm{O}$ with or without the metal ions, respectively).

measured with the presence of the metal ions in $\mathrm{D}_{2} \mathrm{O}$, respectively. Due to the interaction between the $\mathrm{D}_{2} \mathrm{O}$ and HPEAMMBA, the signals corresponding to $\mathrm{C}=\mathrm{O}$ and $\mathrm{N}-\mathrm{H}$ shift to the lower wavenumber region. For $\mathrm{Na}^{+}, \mathrm{K}^{+}, \mathrm{Mg}^{2+}$ and $\mathrm{Ca}^{2+}$, the characteristic adsorptions of $\mathrm{N}-\mathrm{H}$ shifted to the lower wavenumber region, while the vibrational peak of $\mathrm{C}=\mathrm{O}$ stretching unchanged, which indicates that the addition of $\mathrm{Na}^{+}, \mathrm{K}^{+}, \mathrm{Mg}^{2+}$ and $\mathrm{Ca}^{2+}$ promotes the dissociation of amide group. As the $\mathrm{Zn}^{2+}$, the characteristic adsorptions of $\mathrm{C}=\mathrm{O}$ and $\mathrm{N}-\mathrm{H}$ shifted from $1634 \mathrm{~cm}^{-1}$ to $1651 \mathrm{~cm}^{-1}$ and $1450 \mathrm{~cm}^{-1}$ to $1472 \mathrm{~cm}^{-1}$ respectively. Evidently, the $\mathrm{Zn}^{2+}$ binds with not only $\mathrm{N}$ atom, but also the $\mathrm{O}$ atom which can be due to its $3 \mathrm{~d}^{10}$ electron configuration. Therefore, $\mathrm{Zn}^{2+}$ shows a much stronger salting-in effect as comparing to those of other metal ions.

Because that the HPEAM-MBA solution shows the feature of selectively recognizing the $\mathrm{Zn}^{2+}$ as the environment temperature is 20 degrees higher than the LCST, the HPEAM possessing lower LCST was selected as the platform to copolymerize with 
TPEAH. The TPE-bearing polymer was synthesized by using reversible addition-fragmentation chain-transfer polymerization (RAFT). It shows a highly specific response over other metal ions. The mechanism of polymerization was shown in Scheme 2 and the detail was shown in ESI. $\dagger$ The resulting copolymer HPEAM-TPEAH(with yield as 57\%.) was characterized by FTIR, and ${ }^{1} \mathrm{H}$ NMR, and the detailed assignment is shown in ESI. $\dagger$ The ratio of EAM $\backslash$ TPEAH is 2.9 on basis of the ${ }^{1} \mathrm{H}$ NMR results.

The HPEAM-TPEAH is difficult to be dissolved in water, while the aqueous system containing HPEAM-TPEAH displays an obvious fluorescence emission which can be owing to the aggregation-induced emission (AIE) effect of TPE units. Generally, the incorporation with metal ions would raise the solubility of the polymers in aqueous system and thereby result in the decreasing of fluorescence intensity, which can be named as the "turn off" response. The "turn off" response of HPEAM-TPEAH on the metal ions including $\mathrm{Zn}^{2+}, \mathrm{Mn}^{2+}, \mathrm{Na}^{+}, \mathrm{K}^{+}, \mathrm{Ca}^{2+}, \mathrm{Mg}^{2+}$ and $\mathrm{Fe}^{2+}$ were investigated respectively. The results depicted on ESI $\dagger$ shows that the "turn off" response is hard to be detected for $\mathrm{Mn}^{2+}, \mathrm{Na}^{+}, \mathrm{K}^{+}, \mathrm{Ca}^{2+}, \mathrm{Mg}^{2+}$ and $\mathrm{Fe}^{2+}$, while the addition of HPEAM-TPEAH into the $\mathrm{Zn}^{2+}$ solution triggers a dramatically decrease in fluorescence intensity. Furthermore, a simulate body fluid (Na: $140 \mathrm{mmol} \mathrm{L}{ }^{-1} ; \mathrm{K}^{+}$: $5.5 \mathrm{mmol} \mathrm{L}{ }^{-1} ; \mathrm{Ca}^{2+}$ : $1.33 \mathrm{mmol} \mathrm{L}{ }^{-1} ; \mathrm{Mg}^{2+}$ : $5 \mathrm{mmol} \mathrm{L}{ }^{-1} ; \mathrm{Fe}^{2+}$ : $3.0 \mathrm{mmol} \mathrm{L}{ }^{-1}$ ) was prepared, where the "turn-off" cannot be detected with the addition of HPEAM-TPEAH into simulate body fluid (shown in Fig. 6). While the fluorescence intensity significantly decreased as the addition of $\mathrm{Zn}^{2+}$ into the above system. Results of the linear regression for $I_{0}-I$ and $\left[\mathrm{Zn}^{2+}\right]$ show that the linear correlation coefficient $\left(R^{2}\right)$ is greater than 0.99 which indicates that the $I_{0}-I$ and $\left[\mathrm{Zn}^{2+}\right]$ shows a good linearity relationship in the range from $2 \times 10^{-6}$ to $2 \times 10^{-5} \mathrm{~mol} \mathrm{~L}^{-1}$ (details were shown in ESI $\dagger$ ). The results show that HPEAM-TPEAH exhibits a highly specific "turn-off" response of $\mathrm{Zn}^{2+}$ over other metal ions.

As aforementioned result shows that the $N_{\mathrm{Zn}^{2+}}$ or the concentration of $\mathrm{Zn}^{2+}\left(\left[\mathrm{Zn}^{2+}\right]\right)$ can affect the LCST of HPEAM-

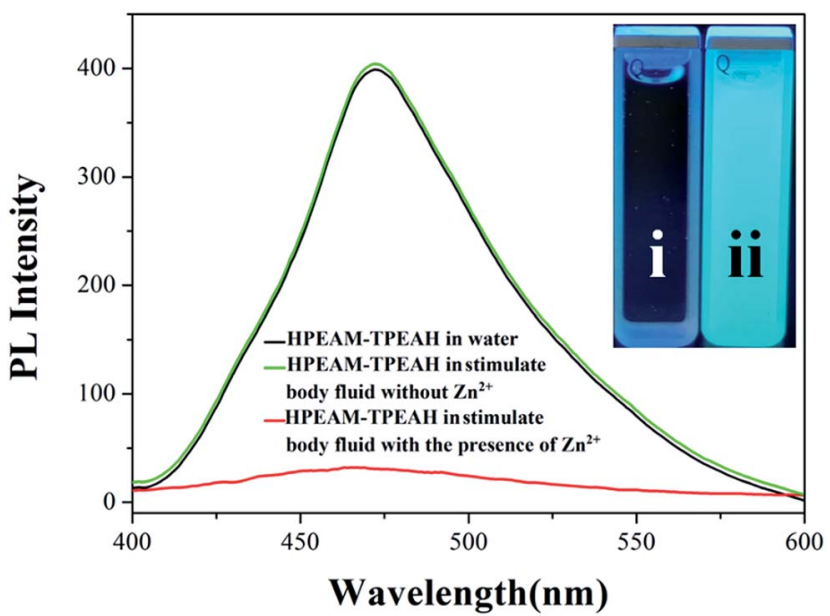

Fig. 6 Fluorescence intensity curves of HPEAM-TPEAH under simulate body fluid with (i) or without $\mathrm{Zn}^{2+}$ (ii). The simulate body fluid contains $140 \mathrm{mmol} \mathrm{L}{ }^{-1} \mathrm{Na}^{+}, 5.5 \mathrm{mmol} \mathrm{L}{ }^{-1} \mathrm{~K}^{+}, 1.33 \mathrm{mmol} \mathrm{L}{ }^{-1} \mathrm{Ca}^{2+}$,

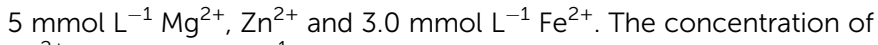
$\mathrm{Zn}^{2+}$ is $0.02 \mathrm{mmol} \mathrm{L}^{-1}$.
MBAs, which means $\left[\mathrm{Zn}^{2+}\right]$ can tune the confirmation of the HPEAM-MBAs. Therefore, the $\left[\mathrm{Zn}^{2+}\right]$ should be associated with the PL intensity of HPEAM-TPEAH. As shown in Fig. 7, along with the increase of $\left[\mathrm{Zn}^{2+}\right]$, the PL intensity gradually decrease. When the $\left[\mathrm{Zn}^{2+}\right]$ reaches $0.02 \mathrm{mmol} \mathrm{L}{ }^{-1}$, the PL intensity is very low and keeps unchanged even if the $\left[\mathrm{Zn}^{2+}\right]$ is higher. The relationship of PL intensity and concentration of other metals was also investigated and the corresponding curves are shown in ESI. $\dagger$ The PL intensity of HPEAM-TPEAH solution still unchanged, even if the [metals], including $\mathrm{Na}^{+}, \mathrm{K}^{+}, \mathrm{Ca}^{2+}, \mathrm{Mg}^{2+}$ and $\mathrm{Fe}^{2+}$, reaching $100 \mathrm{mmol} \mathrm{L}^{-1}$. The accuracy of the detection of $\mathrm{Zn}^{2+}$ by using HPEAM-TPEAH is also evaluated. The plots of $\left[\mathrm{Zn}^{2+}\right]$ against $I_{0}-I$ are displayed in Fig. 8, where $I_{0}$ represents the initial PL intensity, and $I$ is the PL intensity under the

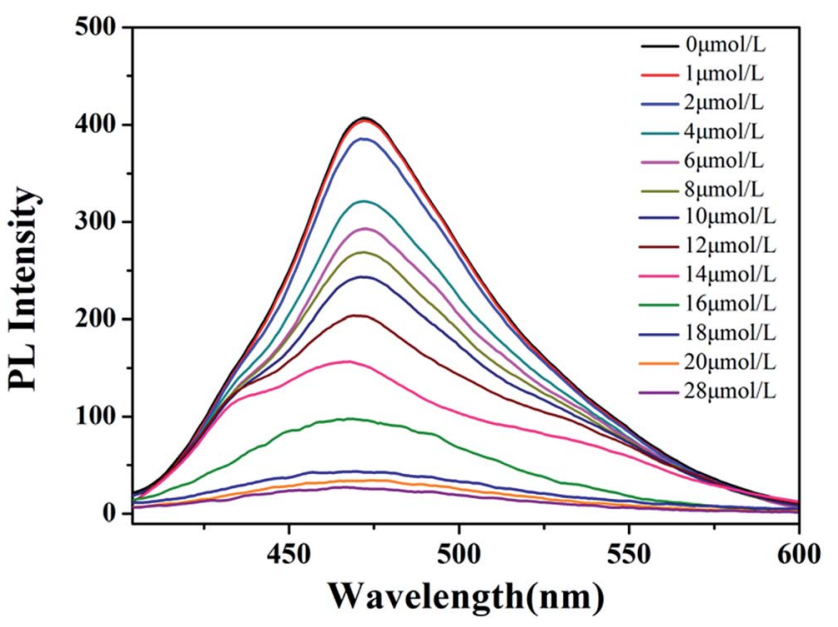

Fig. 7 The curves of PL Intensity vs. $\left[\mathrm{Zn}^{2+}\right]$ of HPEAM-TPEAH. Polymer concentration: $0.125 \mathrm{mg} \mathrm{mL}^{-1}$; test temperature: $25^{\circ} \mathrm{C}$; $\lambda_{\mathrm{ex}}=310 \mathrm{~nm}$.

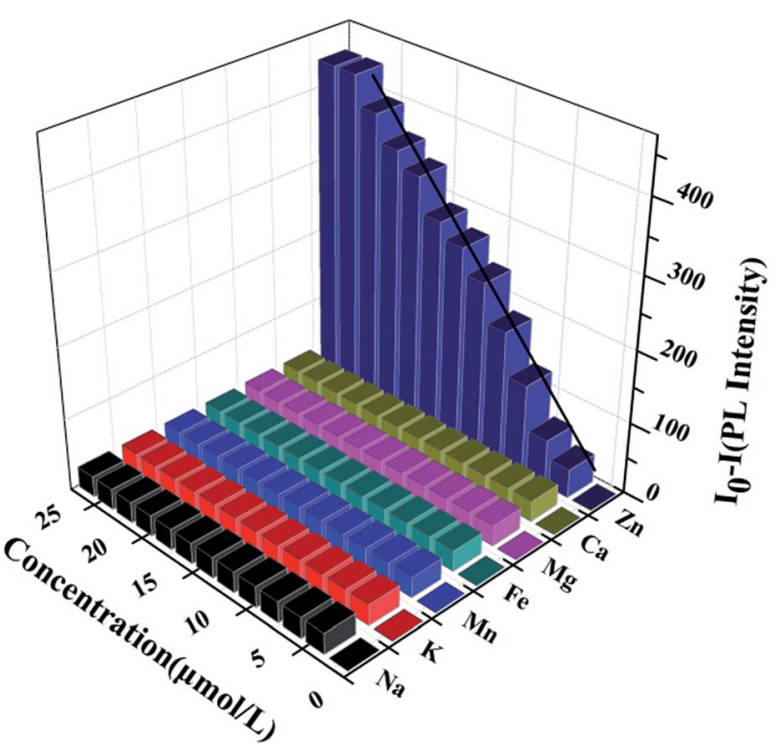

Fig. 8 The three-dimensional histogram of $I_{0}-I V s$. the concentration of metals, which $I_{0}$ represents the initial $\mathrm{PL}$ intensity, and / is the PL intensity under the different concentration of metals. Polymer concentration: $0.125 \mathrm{mg} \mathrm{mL}^{-1}$; test temperature: $25^{\circ} \mathrm{C}$. 


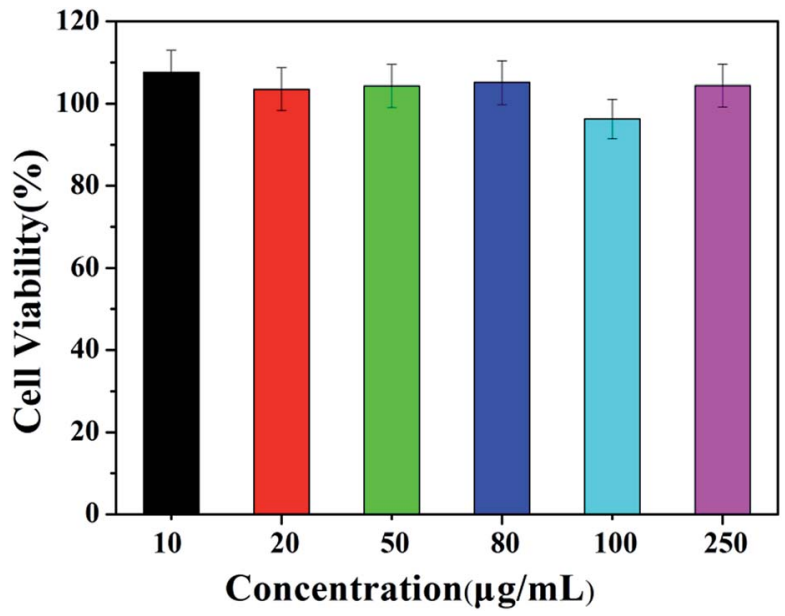

Fig. 9 Cell viability of HPEAM-TPEAH at different concentrations.

corresponding $\left[\mathrm{Zn}^{2+}\right]$. Results of the linear regression for $I_{0}-I$ and $\left[\mathrm{Zn}^{2+}\right]$ show that the linear correlation coefficient $\left(R^{2}\right)$ is greater than 0.995 which indicates that the $I_{0}-I$ and $\left[\mathrm{Zn}^{2+}\right]$ shows a good linearity relationship in the range from $4 \times 10^{-6}$ to $1.8 \times$ $10^{-5} \mathrm{~mol} \mathrm{~L}^{-1}$. Traditionally, the synthesis of polymers bearing the detection capacity upon zinc ions were usually based on the introduction of $\mathrm{Zn}^{2+}$ recognition units into the backbones. ${ }^{15,24,25}$ For an example, the results given by the literature indicated that the detection specificity would be significantly disturbed when the concentration of other metal ions, such as $\mathrm{Na}^{+}, \mathrm{K}^{+}, \mathrm{Mg}^{2+}$ and $\mathrm{Ca}^{2+}$, reaches $50 \mathrm{mM}^{24,25}$ In this study, HPEAM-TPEAH was prepared and used for the detection of $\mathrm{Zn}^{2+}$ based on the interaction between $\mathrm{Zn}^{2+}$ and $\mathrm{N}$ and $\mathrm{O}$ atoms accompanying with the aggregation-induced emission (AIE) effect. The results indicate that HPEAM-TPEAH holds a desirable specificity on the detection of $\mathrm{Zn}^{2+}$ when the concentration of those metal ions reaches $100 \mathrm{mM}$, where the $I_{0}-I$ and $\left[\mathrm{Zn}^{2+}\right]$ shows a good linearity relationship in the range from $2 \times 10^{-6}$ to $2 \times$ $10^{-5} \mathrm{~mol} \mathrm{~L}^{-1}$.

The cytotoxicity of HPEAM-TPEAH was tested by using Hela cells and the results are given in Fig. 9. HPEAM-TPEAH shows very low cytotoxicity (over 95\% cell viability) within $24 \mathrm{~h}$ of incubation time, in which the concentration ranges from $1.0 \times$ $10^{-6}$ to $5.0 \times 10^{-5} \mathrm{~mol} \mathrm{~L}^{-1}$.

\section{Conclusions}

In summary, a new thermo-responsive hyperbranched copoly(bis( $N, N$-ethyl acryl amide $) /(N, N$-methylene bisacrylamide $))$ (HPEAM-MBA) was synthesized by using RAFT. $\mathrm{Zn}^{2+}$ was found to be able to bind with $\mathrm{N}$ atom and $\mathrm{O}$ atom in the backbone of HPEAM-MBA. When the environment temperature is 20 degrees above the LCST, HPEAM-MBAs solution exhibit high sensitivity in assessing $\mathrm{Zn}^{2+}$, which make it possible to gain a new selectively recognizing system. Furthermore, a new $\mathrm{Zn}^{2+}$ specific fluorescent probe (HPEAM-TPEAH) was developed by the copolymerization of $\mathrm{N}, \mathrm{N}$-ethyl acryl amide and TPEAH in this study. The introduction of TPE units gives a highly specific and sensitive $\mathrm{Zn}^{2+}$-sensitivity to HPEAM-TPEAH, as a result the fluorescence exhibits a highly specific "turn-off" response for $\mathrm{Zn}^{2+}$.

\section{Conflicts of interest}

There are no conflicts to declare.

\section{Acknowledgements}

This work is supported by Nature Science Foundation of China grants $(20904008,21274037,51703048)$ and College of Science and Technology Foundation of Hebei Education Department (2010015, B2010000214, B2014201005) P. R. China.

\section{Notes and references}

1 K. App, J. D. Hounhouigan and N. Mjr, LWT-Food Sci. Technol., 2007, 40, 834-841.

2 N. Sadeghi, M. R. Oveisi, B. Jannat, M. Hajimahmoodi, A. Behfar, M. Behzad, N. Norouzi, M. Oveisi and B. Jannat, Iran. J. Pharm. Res., 2014, 13, 345-349.

3 T. Vengris, R. Binkiene and A. Sveikauskaite, Appl. Clay Sci., 2001, 18, 183-190.

4 X. M. Xie and T. G. Smart, Nature, 1991, 349, 521-524.

5 J. H. Viles, Coord. Chem. Rev., 2012, 256, 2271-2284.

6 M. A. Anderson, F. M. M. Morel and R. R. L. Guillard, Nature, 1978, 276, 70-71.

7 B. D. Korant, J. C. Kauer and B. E. Butterworth, Nature, 1974, 248, 588-590.

8 J. M. Wenzlau, K. Juhl, L. Yu, O. Moua, S. A. Sarkar, P. Gottlieb, M. Rewers, G. S. Eisenbarth, J. Jensen, H. W. Davidson and J. C. Hutton, Proc. Natl. Acad. Sci. U. S. A., 2007, 104, 17040-17045.

9 C. Migliorini, E. Porciatti, M. Luczkowski and D. Valensin, Coord. Chem. Rev., 2012, 256, 352-368.

10 K. J. Barnham and A. I. Bush, Chem. Soc. Rev., 2014, 43, 67276749.

11 A. Zacharia, A. Zhuravlev, S. Gucer, A. Chebotarev, M. Arabadji and A. Dobrynin, J. Food Compos. Anal., 2015, 38, 62-68.

12 J. Peng, W. Xu, C. L. Teoh, S. Han, B. Kim, A. Samanta, J. C. Er, L. Wang, L. Yuan, X. Liu and Y. Chang, J. Am. Chem. Soc., 2015, 137, 2336-2342.

13 L. S. Balistrieri, D. M. Borrok, R. B. Wanty and W. I. Ridley, Geochim. Cosmochim. Acta, 2008, 72, 311-328.

14 M. Ince, O. Er, K. Ocakoglu, F. Y. Lambrecht, S. G. Colak, H. M. Soylu, C. Kayabasi and C. Gunduz, Chem. Biol. Drug Des., 2016, 87, 224-232.

15 P. Jiang and Z. Guo, Coord. Chem. Rev., 2004, 248, 205-229. 16 Z. Guo, G. H. Kim, J. Yoon and I. Shin, Nat. Protoc., 2014, 9, 1245-1254.

17 A. Mazen, G. Gradwohl and M. G. De, Anal. Biochem., 1988, 172, 39-42.

18 D. W. Domaille, E. L. Que and C. J. Chang, Nat. Chem. Biol., 2008, 4, 168-175. 
19 K. D. Belfield, M. V. Bondar, A. Frazer, A. R. Morales, O. D. Kachkovsky, I. A. Mikhailov, A. E. Masunov and O. V. Przhonska, J. Phys. Chem. B, 2010, 114, 9313-9321.

20 A. Ajayaghosh, P. Carol and S. Sreejith, J. Am. Chem. Soc., 2005, 127, 14962-14963.

21 Y. Ding, X. Li, T. Li, W. Zhu and Y. Xie, J. Org. Chem., 2013, 78, 5328-5338.

22 K. P. Divya, S. Sreejith, B. Balakrishna, P. Jayamurthy, P. Anees and A. Ajayaghosh, Chem. Commun., 2010, 46, 6069-6071.

23 K. P. Divya, S. Sreejith, P. Ashokkumar, Y. Kang, Q. Peng, S. K. Maji, Y. Tong, H. Yu, Y. Zhao, R. Perumal and A. Ayyappanpillai, Chem. Sci., 2014, 5, 3469-3474.

24 S. Mizukami, S. Okada, S. Kimura and K. Kikuchi, Inorg. Chem., 2009, 48, 7630-7638.

25 R. A. Bozym, R. B. Thompson, A. K. Stoddard and C. A. Fierke, ACS Chem. Biol., 2006, 1, 103-111.

26 T. Zhang, X. Chen, J. Liu, L. Zhang, J. Chu, L. Su and B. Zhao, RSC Adv., 2014, 4, 16973-16978.

27 X. Meng, S. Wang, Y. Li, M. Zhu and Q. Guo, Chem. Commun., 2012, 48, 4196-4198.

28 E. M. Nolan, J. Jaworski, M. E. Racine, M. Sheng and S. J. Lippard, Inorg. Chem., 2006, 45, 9748-9757.

29 R. Satapathy, Y. H. Wu and H. C. Lin, Org. Lett., 2012, 14, 2564-2567.

30 S. J. A. Aper and M. Merkx, ACS Synth. Biol., 2016, 5, 698-709.

31 A. Zarkan, H. Macklyne, A. W. Truman, A. R. Hesketh and H. Hong, Sci. Rep., 2016, 6, 19602.

32 K. Komatsu, K. Kikuchi, H. Kojima, Y. Urano and T. Nagano, J. Am. Chem. Soc., 2005, 127, 10197-10204.

33 B. Lee, T. K. Chu, K. A. Dill and R. N. Zuckermann, J. Am. Chem. Soc., 2008, 130, 8847-8855.

34 S. Kutsumizu, M. Nakamura and S. Yano, Macromolecules, 2001, 34, 3033-3040.

35 Z. Jia, H. Chen, X. Zhu and D. Yan, J. Am. Chem. Soc., 2006, 1128, 8144-8145.

36 M. Wang, G. Zhang, D. Zhang, D. Zhu and B. Z. Tang, J. Mater. Chem., 2010, 20, 1858-1867.

37 H. Tong, Y. Hong, Y. Dong, M. Häussler, Z. Li, J. W. Y. Lam, Y. Dong, H. H. Y. Sung, I. D. Williams and B. Z. Tang, J. Phys. Chem. B, 2007, 111, 11817-11823.
38 J. Mei, N. L. Leung, R. T. Kwok, J. W. Lam and B. Z. Tang, Chem. Rev., 2015, 115, 11718-11940.

39 R. Hu, N. L. C. Leung and B. Z. Tang, Chem. Soc. Rev., 2014, 43, 4494-4562.

40 H. Shi, N. Zhao, D. Ding, J. Liang, B. Z. Tang and B. Liu, Org. Biomol. Chem., 2013, 11, 7289-7296.

41 P. Li, B. Tang, Y. Xing, P. Li, G. Yang and L. Zhang, Analyst, 2008, 133, 1409-1415.

42 J. T. Lai, A. D. Filla and R. Shea, Macromolecules, 2002, 35, 6754-6756.

$43 \mathrm{C} . \mathrm{Yu}, \mathrm{Y} . \mathrm{Wu}, \mathrm{F} . \mathrm{Zeng}, \mathrm{X} . \mathrm{Li}, \mathrm{J}$. Shi and S. Wu, Biomacromolecules, 2013, 14, 4507-4514.

44 S. Zhou, D. Zhang, L. Bai, J. Zhao, Y. Wu, H. Zhao and X. Ba, Polymers, 2016, 8, 135.

45 Y. Wu, G. Li, L. Bai, W. Li, S. Wang, X. Ba, G. Zhou and H. Zhao, Macromol. Res., 2014, 22, 1196-1202.

46 N. O. Brien, A. McKee, D. C. Sherrington, A. T. Slark and A. Titterton, Polymer, 2000, 41, 6027-6031.

47 Z. Guan, J. Am. Chem. Soc., 2002, 124, 5616-5617.

48 T. Sato, Y. Arima, M. Seno and T. Hirano, Macromolecules, 2005, 38, 1627-1632.

49 T. Sato, Y. Arima, M. Seno and T. Hirano, Polym. Int., 2004, 53, 1138-1144.

50 T. Sato, N. Sato, M. Seno and T. J. Hirano, J. Polym. Sci., Part A: Polym. Chem., 2003, 41, 3038-3047.

51 T. Sato, N. Higashida, T. Hirano and M. Seno, J. Polym. Sci., Part A: Polym. Chem., 2004, 42, 1609-1617.

52 B. Grignard, C. Jérôme, C. Calberg, R. Jérôme, W. Wang, S. M. Howdle and C. Detrembleur, Macromolecules, 2008, 41, 8575-8583.

53 C. Zhang, Y. Zhou, Q. Liu, S. Li, S. Perrier and Y. Zhao, Macromolecules, 2011, 44, 2034-2049.

54 J. Kong, T. Schmalz, G. Motz and A. Müller, Macromolecules, 2011, 44, 1280-1291.

55 P. N. Lo and B. M. Ninham, Chem. Rev., 2012, 112, 22862322.

56 K. B. Rembert, J. Paterova, J. Heyda, C. Hilty, P. Jungwirth and P. S. Cremer, J. Am. Chem. Soc., 2012, 134, 10039-10046.

57 J. Kherb, S. C. Flores and P. S. Creme, J. Phys. Chem. B, 2012, 116, 7389-7397. 